\title{
O vlog como gênero textual aplicado a questões de ensino de literatura
}

\author{
Rossana Paulino de LUNA ${ }^{1}$ \\ Sinara de Oliveira BRANCO ${ }^{2}$
}

Resumo: O declínio do tradicionalismo no ensino exige do professor novas posturas perante velhos conteúdos. Este artigo discorre sobre uma nova tendência entre desenvolvedores de vlogs, envolvendo a releitura de determinadas obras literárias, além de apresentar uma proposta de aplicação de tais ideias em aulas de literatura. Levando este fato em consideração, o presente trabalho faz uma breve apresentação do gênero vlog e suas principais características enquanto gênero textual aplicado ao ensino (LIMA; LUNA, 2012). Depois da apresentação teórica, será realizada uma análise contrastiva entre a obra "Orgulho e Preconceito", de Jane Austen, e a sua adaptação para o vlog "The Lizzie Bennet Diaries". Com isso, espera-se desenvolver um estudo que descreva como os vlogs podem auxiliar professores de língua e literatura a visualizar a possibilidade da utilização do gênero vlog em suas aulas, não apenas para ir além do tradicionalismo vigente nestas aulas, mas também para promover o desenvolvimento de competências interculturais e uma interação efetiva do educando com as obras trabalhadas em sala de aula, proporcionando a sensibilização literária dos alunos.

Palavras-chave: Língua. Literatura. Vlog. Releituras.

Abstract: The decline of traditionalism in education requires from teachers new attitudes towards old contents. This article explains about a new trend among $v \log ^{\prime} s$ developers, involving the reinterpretation of certain literary works, and present a proposal for implementation of such ideas in literature classes. Taking this fact into consideration, this paper makes a brief presentation of the genre vlog and its main features as textual genre applied to teaching (LIMA; LUNA, 2012). Besides the theoretical presentation, it will be done a contrastive analysis between the book "Pride and Prejudice" by Jane Austen, and its adaptation to the vlog "The Lizzie Bennet Diaries". Thus, it is expected to develop a study that describes how vlogs can assist language and literature professors to visualize the possibility of using the genre vlog in their classes, not only to go beyond the prevailing traditionalism in these classes, but also to promote the development of intercultural skills, and effective interaction with the works of the student worked in the classroom, providing literary sensitization of students.

Keywords: Language, Literature, Vlog, Rereading.

\section{BUFFERING: Uma introdução}

A internet, desde o princípio da sua utilização para uso doméstico, se configura como o berço de novos gêneros textuais. Estes são caracterizados pela quantidade de recursos semióticos que podem ser mobilizados no seu desenvolvimento - além de permitirem uma dinâmica de revitalização de antigos gêneros análogos, reiterando a afirmativa de Marcuschi (2010, p. 15) que diz que "os gêneros emergentes nessa nova tecnologia são relativamente

\footnotetext{
${ }^{1}$ Graduanda do curso de Letras Língua Inglesa pela Universidade Federal de Campina Grande (UFCG). Bolsista do Programa de Educação Tutorial do curso de Letras (PET-Letras/UFCG). E-mail: rssnluna@ gmail.com.

${ }^{2}$ Profa. Dra. do Programa de Pós-Graduação em Linguagem e Ensino da Universidade Federal de Campina Grande (PÓS-LE/UFCG). E-mail: sinarabranco@gmail.com.
} 
variados, mas a maioria deles tem similares em outros ambientes, tanto na oralidade quanto na escrita".

Muitos desses gêneros da internet são passageiros e obliterados em virtude do surgimento de novos gêneros que ganham em originalidade e praticidade, estabelecendo-se assim uma seleção natural da Web, na qual é a sobrevivência do mais forte é determinada pelo número de desenvolvedores e usufrutuários. O vlog parece ser um desses gêneros textuais, que foi galgando sua importância e se popularizando entre internautas de todas as idades. Não é possível afirmar se o vlog terá uma vida longa, mas o fato é que, desde seu surgimento em 2003, ele vem se popularizando cada vez mais e ainda não demonstrou sinais de desgaste, ampliando as possibilidades do blog através da mobilização de mais recursos semióticos uma vez que no blog apenas a utilização de textos e imagens são permitidos; enquanto que no vlog filmagem, texto, fotos, áudio, efeitos visuais e de corte se combinam para conceber o produto final em vídeo.

O vlog não se restringe a ser um espaço de opinião sobre apenas uma temática ou grupo fechado de temáticas. Como observaram Lima e Luna (2012, p. 7): "nos gêneros digitais jaz uma potencialidade limitada às fronteiras da imaginação do seu usuário de como se desdobrarem", assim sendo, os vlogueiros não encontrarão muitas barreiras externas no que diz respeito à necessidade de seguir uma receita pré-estabelecida de como e o que "vlogar". Recentemente, uma nova tendência que se tem observado, é a transposição intermidiática de obras literárias. Alguns vloggers criam canais no site "Youtube", onde disponibilizam uma série de vídeos em que perpetuam uma transposição de determinada obra para outro contexto não só midiático, mas temporal e, consequentemente, sócio-cultural. Um desses canais é o "The Lizzie Bennet Diaries", que conta com mais de 100 vídeos, nos quais é feita uma adaptação da obra clássica de Jane Austen (1975-1817), “Orgulho e Preconceito”.

Este artigo almeja, portanto, não só apresentar algumas considerações sobre o vlog enquanto gênero, mas também - e de forma mais detida - pontuar as principais diferenças e possíveis explicações para as escolhas feitas na transposição da obra de Austen para as telas dos internautas do mundo todo; além de conjecturar sobre a seguinte questão: é possível conceber o vlog como uma ferramenta pedagógica produtiva a ser aplicada nas aulas de língua e literatura? No mais, é possível considerar a atividade de elaborar adaptações de clássicos da literatura para o vlog como um instrumento válido de avaliação?

\footnotetext{
${ }^{3}$ Tradução: Os Diários de Lizzie Bennet. Link para acesso:<http://www.youtube.com/user/LizzieBennet>.
} 
Destarte, trazemos primeiramente um histórico do gênero textual em discussão e sua devida caracterização, antes de iniciarmos a análise contrastiva entre o vlog "The Lizzie Bennet Diaries" e a obra "Orgulho e Preconceito", para posteriormente apresentarmos uma proposta de sequência didática e tecer algumas considerações finais.

\section{PLAY}

\subsection{Vlogs}

Apesar de os vlogs já constarem nos registros do país desde 2003, o vlog (videolog, ou ainda, videoblog) popularizou-se no Brasil durante o ano de 2010 e teve sua difusão facilitada pelo site Youtube, lançado em 2005, que oferecia um meio fácil e de qualidade para disseminar vídeos curtos. A dinamicidade, a falta de censura, a irreverência e a brevidade dos vídeos (entre 05 e 15 minutos) atraem principalmente o público jovem, que vê neste gênero uma oportunidade de se fazer ver e ouvir.

O vlog não volta sua funcionalidade para uma temática característica em especial. Uma das principais características do vlog é que "ao contrário da maior deliberação da fala para a escrita existente nos demais gêneros digitais, com os vlogs existe uma dedicação de se conceber a escrita para a fala" (LIMA; LUNA, 2012, p. 6). Outra consideração a ser feita em relação ao gênero é que: “o aspecto conversacional entre videoblogger e telespectador se dá pela linguagem e uso recorrente da terceira pessoa do singular para levantar ações que podem ser desenvolvidas pelos viewers ${ }^{4}$ estabelecendo (sic.) uma ponte direta entre enunciador e ouvinte" (idem, p. 8). A seguir, apresentaremos uma breve descrição da obra aqui estudada.

\subsection{Avaliação}

Hughes $^{5}$ (2005, p. 9) pontua que nós, enquanto professores, "usamos testes para obter informação. A informação que nós esperamos obter, obviamente, variará de situação para situação". Este olhar de Hughes sobre o objetivo dos testes não é apenas sucinto, mas também denota certa neutralidade sócio-histórica e política na utilização dos processos avaliativos, a qual não desponta a realidade de todas as implicações dos processos avaliativos.

\footnotetext{
${ }^{4}$ Tradução: Visualizadores

5 Tradução própria.
} 
Como Luckesi (2011), escreve:

\begin{abstract}
"Michel Foucault, em seu livro Vigiar e Punir, nos lembra que, com o final dos mecanismos inquisitoriais, públicos e teatrais, do final da Idade Média, passamos, na emergência da modernidade, para os mecanismos de disciplinamento através de micropoderes, que são recursos silenciosos de controle das pessoas e de grupos humanos, que operam no seio das instituições sociais.

A escola é uma dessas instituições e os exames um desses recursos. Os exames escolares, da forma como existem hoje, desde que foram sistematizados no século XVI, carregam uma carga de ameaça e castigo sobre os educando, cujo objetivo é pressioná-los, para que disciplinadamente estudem, aprendam e assumam condutas, muitas vezes, além de externas a eles mesmos, também aversivas" (p. 68)
\end{abstract}

Por essa passagem do escrito de Luckesi (2011) observamos que os grilhões de cinco séculos de história nos impedem muitas vezes de enxergar a verdade que está um pouco além do horizonte: "os exames escolares, hoje, não nos ajudam a produzir resultados escolares bem-sucedidos" (LUCKESI, 2011, p. 69); ademais, por vezes, esquecemos que a função dos exames e testes deveria ser nos permitir acompanhar o desenvolvimento e as carências educacionais dos estudantes.

No Brasil, a Lei n. 9.394, de 20 de dezembro de 1996, nomeada Lei de Diretrizes e Bases da Educação Nacional, apregoa uma: "avaliação contínua e cumulativa do desempenho do aluno, com prevalência dos aspectos qualitativos sobre os quantitativos e dos resultados ao longo do período sobre os de eventuais provas finais." (BRASIL, 1996, art. 24, inciso V, alínea a).

Entretanto, como bem observa Luckesi (2011), na prática escolar contemporânea, notas e conceitos se convertem em indicadores da qualidade que se atribui à aprendizagem do aluno, estas notas são (geralmente) medidas sob a forma de acertos ou pontos em exames que são deveras objetivos. A motivação da ação de estudar do alunado é o alcance da média mínima de nota, que caso seja menor do que a média estipulada pela instituição, impedirá o avanço do estudante para a próxima série. Já o professor, fará uso dessa nota registrando-a na caderneta de alunos, oferecerá ao educando a chance de recuperação, ou irá atentar para as deficiências na aprendizagem dos alunos tentando, promover um ensino efetivo e suprindo essas deficiências.

Nestas condições, o que Luckesi (2011) argui é que, tanto a ação dos alunos quanto a ação remediadora do professor, voltam-se para obtenção da média mínima de notas. O autor 
não desconsidera que o estudo visando à melhora da nota pode levar ao aprendizado também, o argumento do autor é: se o estudo visa apenas à nota e desconsidera o aprendizado, do ponto de vista educativo está promovendo uma concepção desviante do processo educacional, pois a avaliação não deve servir de meio classificatório entre aprovados e reprovados, mas estar a serviço do desenvolvimento do educando.

No mais, a média mínima de notas é enganosa. Pernigotti et. al. (2000) trazem as seguintes considerações:

\begin{abstract}
"Sempre nos questionamos sobre a propriedade de usar as provas como ponto básico para a avaliação, pois, se os alunos só precisam "apresentar" seu conhecimento uma vez por mês ou por bimestre, como ficam os outros dias de aula? Serão menos importantes? Por outro lado, de que valem os saberes adquiridos, mas que não caíram na prova? Será que eles são menos importantes? Além disso, de que adianta constatar "deficiências" de aprendizagem quando o "tempo para trabalhar aquele assunto" já se esgotou? Percebemos que muitos professores se sentem seguros em afirmar que um aluno sabe algum conteúdo se ele o reproduziu em uma prova, mas será que isso é verdade? Todos que passamos pelo $2^{\circ}$ grau, como alunos, respondemos uma prova sobre função quadrática, porém, poucos de nós, hoje, somos capazes de dizer o que ele significa, ou mesmo a fórmula usada para resolver questões que envolvam essa função. Seria demais afirmar que 'uma prova não prova nada'?” (p.1).
\end{abstract}

Relacionada a essas ideias está a acepção de Luckesi (2011, p. 55-56) de que o que deveria importar é o estabelecimento de: "um padrão mínimo de conhecimentos, habilidades e hábitos que o educando deverá adquirir, e não uma média mínima de notas, como ocorre hoje na prática escolar.” Ou seja, Luckesi (2011, p. 150) promove o imperativo de uma aprendizagem intencional, ativa e inteligível: "a aprendizagem reflexa é o oposto de uma aprendizagem ativa e inteligível e insuficiente ou quase nula para o desenvolvimento do educando".

Devemos lembrar ainda que aos conteúdos socioculturais, que compõem o currículo, subjazem 1) uma metodologia técnica ou teórica e 2) visões valorativas (inclusive as do professor). Pernigotti et. al. (2000) observam:

"Geralmente, uma prova representa o olhar do professor sobre o conteúdo estudado. Não contempla os múltiplos caminhos que um aluno pode percorrer para realizar suas aprendizagens.

Além disso, é preciso que se considere o aluno em todos os momentos nos quais interage com diferentes pessoas e situações escolares. Dessa forma, teremos a chance de compor uma "avaliação" mais consistente". 
A escola não pode viver sempre reproduzindo situações de concursos, pois ávida, para a maioria das pessoas, não é feita só deles, mas sim de muitas e muitas situações de interação, onde nossos conhecimentos são postos em xeque e outros tantos precisam ser construídos. É importante prepararmos os alunos para enfrentar situações de testagem sim, mas a escola deve preocupar-se em enfatizar outras situações, nas quais eles possam manter um real diálogo com o conhecimento" (p. 2).

A citação de Pernigotti et. al. (2000) relaciona-se com o que Luckesi (2011, p. 157) assevera sobre a necessidade de: "cuidar criticamente dessas visões de mundo ao trabalhar com os educandos no processo de ensino, para que eles não assumam ingenuamente visões de mundo que venham a limitar suas formas de compreender a realidade e limitar suas vidas"; de tal modo que o educando apto a simplesmente reportar reflexamente as informações e conteúdos, que lhe foram passados, nada aprendeu. Aprendizado requer compreensão, filtro e manipulação dos conhecimentos e o processo avaliativo deve ser capaz de promover a demonstração de que o aluno é competente nesses aspectos.

\subsection{Orgulho e Preconceito}

Desde a sua primeira publicação, em 1813, "Orgulho e Preconceito" nunca deixou de fazer sucesso e ser aclamado como um dos melhores romances de todos os tempos. A obra da autora britânica, Jane Austen, narra a vida da família Bennet, tendo como personagem principal a jovem Elizabeth Bennet - a segunda das cinco filhas do Sr. e Sra. Bennet.

A história começa quando a mansão de Netherfield é ocupada por um abastado jovem solteiro, Mr. Bing, sua irmã mais velha acompanhada do marido, sua irmã mais nova e um amigo da família, Mr. Darcy: um homem altivo e reservado, ainda mais rico do que Mr. Bing. A Sra. Bennet vê, então, uma oportunidade de casar (e muito bem) suas filhas, de forma a não deixá-las desamparadas após a morte do Sr. Bennet.

Em um baile, as jovens Bennet são apresentadas ao Mr. Bing e sua família, além de Mr. Darcy. Jane, a primogênita, logo atrai os olhares de Mr. Bing. Elizabeth, contudo, teve uma noite bem menos agradável, entreouvindo um comentário pejorativo de Mr. Darcy sobre a sua pessoa. Ao final do baile, Elizabeth chega à conclusão de que Mr. Darcy é o homem mais odioso de todos e passa a tratá-lo com uma incivilidade impertinente a cada encontro pouco ansiado com o mesmo. Paradoxalmente, Mr. Darcy é o único homem capaz de desposá-la. 
Pouco tempo depois, Elizabeth conhece George Wickham, um soldado que se mostra aprazível e revela uma aversão profunda por Mr. Darcy, culpando-o por todos os seus infortúnios. Como se nada unisse mais duas pessoas do que o ódio em comum por alguém, os dois desenvolvem uma amizade baseada, principalmente, em reprimendas acerca do comportamento passado e presente de Mr. Darcy. Decorrido mais algum tempo, Mr. Darcy, Mr. Bing e os outros familiares abandonam a mansão de Netherfield sem qualquer explicação, para decepção de Jane, da Sra. Bennet e de Elizabeth, que fica preocupada com o estado emocional da irmã. Elizabeth convence-se que tudo não passa de um estratagema de Darcy e da irmã mais nova de Bing, Caroline, que desaprovavam a inclinação de Mr. Bing por Jane, uma moça de recursos e fortuna escassos e, portanto, abaixo da sua posição social.

Algum tempo depois, Darcy e Elizabeth se reencontram e, então, o profundo amor contrariado que o arrogante homem nutria pela moça é revelado. Ele a pede em casamento e é friamente repelido por ela, que faz questão de apontar cada um dos seus vis atos para com a irmã e para com George Wickham. Mr. Darcy, ainda que ferido, procura uma oportunidade para se justificar perante Elizabeth, através de uma carta, explicando que separara Bing da jovem Jane por acreditar que ela era indiferente ao amor dele, e narrando os malefícios que Wickham trouxera para ele e sua irmã, Georgiana. Logo depois, Mr. Darcy parte. Não podendo rechaçar os argumentos passíveis de comprovação dele, ela reconhece o quão tola havia sido e passa por um período de reflexão, que a leva ao amadurecimento. Os dois voltam a se reencontrar e, dessa vez, Darcy toma todas as medidas necessárias para se redimir aos olhos da amada. Seu principal mérito é unir Jane a Bing e trazer para casa a jovem Lydia, a mais nova das filhas Bennet, que havia fugido com Wickham sem contrair casamento, uma desonra que se estenderia a toda a família.

Finalmente, Elizabeth se rende a sua crescente estima por Mr. Darcy e anui em casarse com ele, apesar da desaprovação de Lady Catherine, a tia do seu adorado e uma poderosa mulher que acredita ser desonrosa a união das famílias Darcy e Bennet. Nada disso tem importância, e o casal encontra sua felicidade conjugal, superando os sentimentos mesquinhos de orgulho e preconceito sobrepujando-os com o amor que sentem um pelo outro. A seguir, apresentaremos a adaptação dessa história para o vlog The Lizzie Bennet Diaries.

\subsection{The Lizzie Bennet Diaries}


O canal “The Lizzie Bennet Diaries” fez suas estreia no site Youtube em abril de 2012 e contava, até maio de 2013, com mais de 200.000 inscritos. O último vídeo ("The End Episode 100") foi postado em março de 2013 e teve mais de 400.000 visualizações. "The Lizzie Bennet Diaries", como já foi esclarecido, é uma adaptação modernizada do clássico romance de Jane Austen, "Orgulho e Preconceito", tendo Hank Green e Bernie Su como desenvolvedores. O canal era atualizado duas vezes por semana, com episódios durando entre cinco e dez minutos, e servindo como uma janela para os "voluntários espiões"7 da vida da família Bennet. O romance de Austen, dessa vez, é contado pela perspectiva de Elizabeth "Lizzie" Bennet, que cresceu no mundo dos celulares, câmeras digitais, computadores e mídias sociais. Ela recebe visitas ocasionais dos demais personagens ou ela os personifica, atentando para a personalidade, maneirismos e vestuário dos mesmos.

Não é nesse aspecto, contudo, que o canal inova. O filme "As patricinhas de Beverly Hills" "(1995) é uma adaptação modernizada de outro clássico de Jane Austen, Emma. Já o filme "10 coisas que eu odeio em vocệ" (1999) é uma adaptação do livro "A Megera Domada", por William Shakespeare; por sua vez, o filme “A Mentira ${ }^{10 "}$ (2010) tem fortes relações com a obra de Nathaniel Hawthorne, A Letra Escarlate - como dispositivo de enquadramento da história, a personagem principal (Olive) narra através de um vídeo online (o www.freeolivep.com) os mal-entendidos que levaram ao fim sua boa reputação.

Os desenvolvedores inovaram justamente no uso das demais mídias sociais, não só como ferramenta de divulgação, mas para criar a ilusão de que os personagens são reais e que se pode interagir online com os mesmos. A personagem principal Lizzie Bennet, por exemplo, mantém um Twitter, um perfil no Facebook e um blog no Tumblr, além da conta no YouTube.

\footnotetext{
${ }^{6}$ Tradução: O Fim- Episódio 100. Link para acesso: 〈http://www.youtube.com/watch?v=Kh5AcIAP6iU>

7 “Todo homem é cercado por uma vizinhança de espiões voluntários." (AUSTEN, 2011 a 211)

${ }^{8}$ Dirigido por Amy Heckerling, o filme conta a história de Cher, uma adolescente (Alicia Silverstone), a filha de um rico advogado (Dan Hedaya) que passa seu tempo em conversas fúteis, e bancando o cupido entre seus amigos. O convivio com o enteado do pai (Paul Rudd) desperta a jovem para assuntos mais graves do que as tendências de moda da última estação.

${ }^{9} \mathrm{O}$ filme narra a vida na casa da família Stratford. Bianca (Larisa Oleynik) é famosa entre os garotos, mas seu pai (Larry Miller) não permite que ela namore. Após muita insistência, o pai toma uma resolução: Bianca pode namorar assim que sua irmã, Katharina (Julia Stiles) comece a namorar. Só que Katharina é tida como a megera da escola, uma garota introvertida, independente e que afugenta todos os pretendentes. Para resolver a questão, Cameron (Joseph Gordon-Levitt), apaixonado por Bianca, arruma um modo de custear Patrick Verona (Heath Ledger) na empreitada de fazer Katharina se apaixonar.

${ }^{10}$ Olive (Emma Stone) era uma estudante modelo, mas despercebida pelo corpo estudantil de sua escola. Sua única amiga éRhiannon (Alyson Michalka), que um dia a convida para passar um fim de semana acampando, Olive se desvencilha do compromisso dizendo que tem um encontro com um rapaz no fim de semana. Na segunda seguinte Rhiannon indaga sobre encontro e, para manter a história, Olive diz que perdeu a virgindade com ele. A notícia é ouvida por Marianne (Amanda Bynes), uma fervorosa protestante, que logo a espalha para os demais alunos. A partir de então, Olive passa a ter a fama da nova "vadia" da escola. O filme é dirigido por Will Gluck.
} 
A irmã mais nova, Lydia Bennet também tem um blog, Tumblr e Twitter; Jane Bennet mantém contas no Pinterest e Lookbook, além de outros sites de mídia social. Os fãs/telespectadores são estimulados a interagir com seus personagens favoritos em qualquer plataforma de mídia e buscar as interações feitas entre os personagens nas citadas mídias sociais.

\subsubsection{Algumas adaptações no enredo}

Logo no começo do primeiro episódio ( "My name is Lizzie Bennet ${ }^{11}$ ”), Lizzie mostra uma camiseta - um presente de natal da Sra. Bennet dado às três filhas - com os dizeres: "É uma verdade universalmente conhecida que um homem solteiro na posse de uma boa fortuna deve estar à procura de uma esposa"12. Lizzie prontamente assegura que nunca vai usar tal camiseta e se apresenta como uma jovem de 24 anos, universitária, cheia de empréstimos estudantis e se preparando para construir uma carreira profissional, criticando o fato de que o único interesse da mãe é acabar com a solteirice da filha.

Até esse ponto, não existem muitas mudanças. Na verdade, nenhuma mudança real é feita na essência do caráter dos personagens: Lizzie, interpretada por Ashley Clements, ainda se mostra uma obstinada e independente mulher; Jane (Laura Spencer) é retratada como uma terna fashionista incapaz de pensar mal de alguém; Lydia (Mary Kate Wiles) é uma animada adolescente que nunca se importa com as consequências; Darcy (Daniel Gordh) é um orgulhoso empresário; Bing (Bing Lee, vivido por Christopher Sean) é um estudante de medicina subserviente aos amigos e família; Caroline Bing (Jessica Jade Andres) é uma afetada "amiga"; Charlotte (Lu, não Lucas, interpretada por Julia Cho) é uma amiga devotada, mas racional, com ainda mais dificuldades financeiras do que Lizzie Bennet; e George Wickham (Wes Anderhold) é um belo nadador, com um passado obscuro de dissimulações e trapaças. Na verdade, assistindo aos episódios, a única mudança na personalidade perceptível foi em Georgiana Darcy (Alisson Paige), que se mostra bem menos submissa à vontade do irmão, conquanto ainda se mostre preocupada com o mesmo e, portanto (eventualmente) interfira diretamente na hora de trazer alguns fatos decisivos à luz do conhecimento de Lizzie Bennet e dos telespectadores.

\footnotetext{
${ }^{11}$ Tradução: Meu nome é Lizzie Bennet. Link acesso: <http://www.youtube.com/watch?v=KisuGP2lcPs>

${ }^{12}$ Do original: "It is a truth universally acknowledged, that a single man in possession of a good fortune must be in want of a wife" (AUSTEN, 2011b, p.1)
} 
O fato de que a essência dos personagens foi mantida prova o quão verossímeis são as pessoas criadas por Jane Austen. Não obstante, os eventos descritos no livro estão sujeitos aos costumes e morais vigentes no começo do século XIX, quando a história foi publicada pela primeira vez. Afinal, era isso que a supracitada escritora britânica fazia: retratava as condições socioculturais da época através de personagens que quebravam as expectativas da sociedade para com eles e assim conseguia o clímax das suas narrativas. Reconhecendo esses fatores, seria difícil conceber algumas das ações dos personagens na obra original como sendo ainda indecorosas.

Não é chocante recusar um pretendente rico hoje em dia, como Elizabeth fez com Darcy. Tal ato renderia tema para fofoca com os amigos. Se um homem demonstrar interesse por uma mulher e desistir logo depois, ele não será um desonrado aos olhos de toda a sociedade, enquanto a mulher cairá em ridículo. No pior dos casos, o rapaz será repreendido secretamente por um grupo de pessoas favoráveis à moça e, eventualmente, os dois encontrarão novos parceiros de flerte. Também não existem fortes regras sociais explícitas que digam que o casamento só é aceitável entre pessoas de mesma classe social. Entretanto, os costumes se fazem presentes e o casamento entre classes se torna regra implícita na sociedade.

O caso da fuga de Lydia com George Wickham para se casarem (o evento mais crítico da história), contemporaneamente, não teria tantas repercussões negativas. Lydia não desonraria sua família, descartando para sempre qualquer possibilidade de suas irmãs se casarem algum dia, pelo fato de ter fugido com um homem e posto em discussão a sua castidade. Entretanto, para a época, o ato trouxe à história sua alteração mais profunda. $\mathrm{Na}$ série "The Lizzie Bennet Diaries", o escândalo é causado quando Lydia foge com Wickham para uma temporada de festas, resultando em desconcertantes consequências.

O episódio 85 ("Consequences"13, postado em fevereiro de 2012) mostra uma preocupada Lizzie esperando o retorno de Lydia para falar sobre alguns vídeos contendo cenas de sexo entre sua irmã mais nova e George Wickham, que estão para ser postados na internet em um site, no dia dos namorados nos EUA - dia 14 de fevereiro. Lydia fica chocada ao reconhecer o quanto tinha sido ludibriada por George que, como Lizzie aponta, "tem um histórico de fazer mulheres inteligentes cometerem burrices" ${ }^{\prime 14}$. A partir daí, decorre um período negro na vida das irmãs Bennet. Wickham está desaparecido e não há como retirar o

\footnotetext{
${ }^{13}$ Tradução: Consequências. Link para acesso: <http://www.youtube.com/watch?v=97SJYdxQPcg>

${ }^{14}$ Do original: "George has a history of convincing smart women to do dumb things". (2:09 - 2:12).
} 
site do ar, mas, enfim, no episódio 88 chega a boa notícia de que alguém retirou o site do ar. O mistério concentra-se no quando e em que circunstâncias Darcy se torna o responsável por remediar a terrível situação da irmã mais nova de sua amada Lizzie Bennet, bem como a maneira que Lizzie utilizará para descartar sua indiferença à dedicação de Darcy em relação à felicidade dela e da sua família.

\section{O vlog no contexto da sala de aula}

Um dos discursos mais em voga nas esferas educativas é a questão levantada por Magnabosco (2009):

\footnotetext{
"Com a introdução das novas tecnologias e, principalmente da Internet, novas condutas são necessárias aos educadores para que consigam utilizar essas ferramentas de modo que elas se tornem aliadas ao ensino e a aprendizagem. Faz-se necessário, então, que os professores, além do necessário conhecimento destas tecnologias, utilizem essas ferramentas não só como apoio metodológico, mas também, como uma forma de desenvolver no educando uma postura crítica frente ao ato de ler e escrever" (p. 95).
}

O caráter espontâneo do gênero em questão é atrativo para os jovens (LIMA; LUNA, 2012), e serve como deixa para os alunos realizarem uma atividade não só instrutiva, mas que também servirá para entretenimento e envolvimento entre os demais colegas de sala. Além disso, é necessário que o professor se insira no mundo de tecnologias atual, porque seus alunos não deixarão de fazê-lo.

Este trabalho tem o objetivo de ir além da divulgação dos vlogs, buscando causar uma reflexão acerca de que maneira essa iniciativa dos produtores do projeto "The Lizzie Bennet Diaries" pode vir ao auxílio do processo de ensino/aprendizagem nas aulas de literatura. Uma sugestão parece ser levar o aluno a ler as obras literárias, interagindo de forma efetiva com a obra. Assim, seguiremos com uma proposta de trabalho com o vlog, voltado para as aulas de Literatura.

\subsection{O vlog como gênero textual aplicado a questões de ensino de literatura}

A proposta é levar os alunos a fazerem uma imersão na obra, mas não como se esta fosse um produto acabado e sem significado real. Basicamente, os alunos deverão escolher uma obra literária e transformá-la em um vlog. "The Lizzie Bennet Diaries" fez uma 
articulação com a obra original em sentido temporal, mas outras perspectivas podem ser observadas, por exemplo: a perspectiva sócio-econômica, perspectiva regional, perspectiva cultural, etc.

O importante é que os alunos possam fazer uma ponte entre o que está escrito, a vivência deles e as condições que os cercam, obtendo espaço para se:

“[...] trabalhar além da função comunicativa e das funções linguísticas, para que se encontre um modo de abrir espaço para as discussões de temas inerentes a esses textos. Em outras palavras, é trabalhar o lado 'sujeito inserido num mundo globalizado' dos estudantes, para que dessa forma eles possam conhecer a cultura do outro e relacionar com a sua, ver a língua estrangeira, mas também conhecer o estrangeiro falante dessa língua" (LIMA, PINEIRO-MARIZ, 2012, p. 6).

A obra em questão não precisa ser um romance, a não ser que o professor/a procure fazer um trabalho mais extenso. Crônicas, contos, poesias podem dar margem a este tipo de trabalho também. Os alunos devem captar a essência dos escritos e fazer uma releitura dos mesmos utilizando o gênero vlog. A partir da obra é que o professor deverá traçar um plano específico para a execução da atividade.

\subsection{Aplicação da atividade}

O primeiro passo será a designação da(s) obra(s). O professor deve conhecer as obras e os temas que podem ser ressaltados e explorados pelos alunos em seus vlogs. O grupo poderá se envolver com o mesmo projeto, mas talvez seja preferencial que vários grupos pequenos realizem trabalhos em cima de textos diversos - dependendo do número de componentes da turma.

O professor, então, familiarizará os alunos com o gênero de vlog aqui apresentado, levando um dos vídeos para que os alunos observem certas características que poderão auxiliar no encaminhamento de suas atividades. Será, então, explicitada a proposta de atividade.

A partir dessa introdução, será desvendado o que se requer dos estudantes, detalhando um plano de ação específico, previamente elaborado pelo professor (contendo a quantidade, a duração, prazo e datas de apresentação dos vídeos que serão gravados), e dar margem para os alunos soltarem sua criatividade na releitura dos vídeos e colocarem as suas identidades na produção deles. 
Será interessante que o professor ou os grupos designem uma pessoa responsável pela direção, roteiro e figurino dos vídeos, mas lembrando que todos os alunos deverão se articular para tomar as decisões de forma coerente, e que a responsabilidade de um não ausenta os demais sobre qualquer aspecto referente à produção do trabalho. A atividade deverá, por conseguinte, ter um aspecto colaborativo. É importante que o professor fique atento as decisões dos alunos, sem, contudo, fazer interferências capazes de tolher a atividade dos mesmos, de modo a agir como guia e não como autoridade na execução da tarefa a eles sugerida.

Alguns alunos poderão detectar os temas centrais de uma obra e fazerem relações com o contexto em que vivemos (talvez trazendo alguns pontos que o professor ou estudiosos da obra não identificaram), outros não. No entanto, se este for o caso, o professor pode fazer algumas perguntas instigadoras acerca da obra e deixá-las para reflexão dos alunos. Não é aconselhável assumir uma posição de único detentor do saber, mas provocar os alunos para que estes sejam ativos na construção dos seus próprios saberes.

O educador poderá solicitar, ainda, que os alunos façam um resumo da obra original e de seus aspectos centrais, bem como uma breve explanação do momento histórico da obra, de forma a contextualizar os demais estudantes e permitir que estes vejam a articulação entre a obra original e a releitura em vlog. Enfim, o produto do esforço dos alunos deverá ser apresentado para o restante da turma. Os estudantes poderão, ainda, postar seus trabalhos online e criar perfis em redes sociais para os personagens, promovendo a abertura de feedback para visualizadores externos ao ambiente da sala.

\subsection{Avaliação da Atividade}

O professor poderá usar a atividade como pré-requisito para estabelecer uma nota total ou parcial. Acredito que esta seja uma maneira mais eficaz de avaliar a compreensão da obra pelos alunos, do que um teste escrito, uma vez que o trabalho aqui proposto requer um ativo trabalho mental (uma aprendizagem acompanhada em seu desenvolvimento), ao invés da capacidade de absorver e reproduzir um conhecimento já pronto (aprendizagem de domínio). Não que a aprendizagem voltada para o domínio seja desnecessária, mas ela deve estar inserida dentro de um processo de aprendizagem que leve os alunos um pouco mais além.

“A aprendizagem para o 'desenvolvimento' [...] é o 'mais' (o 'plus'), o que vai para além do estritamente necessário, vai para além do reino necessário e 
ingressa no reino do criativo [...] Isso deve ser ensinado e treinado em nossos estudantes e, por isso mesmo, não só esperado deles nas ocasiões de aplicação de instrumentos para a coleta de dados sobre o seu desempenho, tendo em vista a avaliação da sua aprendizagem. Aprende-se a arriscar para além do que já se aprendeu, mas, para isso, importa investir na exercitação prática" (LUCKESI, 2011, p. 253-254).

Luckesi (2011, p. 45) escreve algumas observações acerca do tema "Avaliação", que para ele, "não possui uma finalidade em si; ela subsidia um curso de ação que visa construir um resultado previamente definido". Com isso, o autor cria uma dicotomia: exames escolares de verificação e exames escolares avaliativos. Enquanto o primeiro tem como fim a transformação da medida do aproveitamento escolar em uma mera nota, o segundo visa à aferição mais efetiva da consistência do aprendizado do aluno. Este último é o que deve ser buscado na hora de avaliar o caminhar de uma turma, de forma que as medidas avaliativas de um educador estejam em plena consonância com os preceitos para a avaliação propostos na Lei n. 9.394, previamente apresentada.

\section{Considerações Finais}

Acreditamos que, pela falta de estudos acerca das potencialidades do vlog, esse tenha se tornado um gênero quase que não aplicado nas esferas educativas de Cursos de Letras. Entretanto, a potencialidade do mesmo como auxílio não só para o trabalho de literatura, mas para qualquer competência de aprendizagem referente ao aprendizado de línguas, pode ser observada a partir da proposta de atividade aqui apresentada como apenas um dos meios de se utilizar o vlog em sala de aula.

Esperamos que este artigo possa auxiliar o leitor na visualização de potencialidades do vlog enquanto ferramenta pedagógica e instrumento avaliativo de compreensão e trato do texto literário. O caráter irreverente do gênero é atrativo para os jovens e seu uso pode propiciar um ambiente envolvente de trabalho educacional. Cabe aos professores atentarem para os gêneros midiáticos em que estão inseridos os seus alunos e utilizar os seus meios de forma a incrementar suas aulas (LIMA; LUNA, 2012).

Não é intenção, contudo, sugerir que a inserção desses gêneros, apreciados pelos jovens, tenha como fim apenas manter os alunos atentos ao que é dito, mas sim, levar os estudantes a pensar ativamente, produzindo e buscando ir além do conhecimento que lhes é repassado. Assim, alunos e professores serão verdadeiros parceiros no processo de ensinar- 
aprender, subvertendo a tradição que apregoa que o professor detém o conhecimento e ao aluno cabe meramente reproduzir o que lhe é ensinado.

\section{Referências}

10 Things I Hate about You. Direção: Gil Junger. Roteiro: Karen McCullah Lutz, Kimberly A. Tillman, Kirsten Smith, Mark Irwin. Produção de Andrew Lazar. USA: Walt Disney. 1999. DVD (97 min), son., color.

AUSTEN, J. Northanger Abbey. Porto Alegre: L\&PM, 2011.

AUSTEN, J. Pride and Prejudice. New York: Barnes and Nobles, 2011.

BRASIL. Lei de Diretrizes e Bases da Educação Nacional. Lei no 9394, de 20 de dezembro de 1996. Estabelece as diretrizes e bases da educação nacional. Brasília, DF, 1996.

Clueless. Direção: Amy Heckerling. Roteiro: Amy Heckerling, Bill Pope, Mona May. Produção de Robert Lawrence e Scott Rudin. DVD (60 min), son, color.

Easy A. Direção: Will Gluck. Roteiro: Bert V. Royal Produção de Will Gluck e Zanne Devine. USA: Sony Pictures. 2010. DVD (91 min), son., color.

GREEN, H.; SU, B. The Lizzie Bennet Diaries. Disponível em: <http://www.youtube.com/user/LizzieBennet/videos>. Acesso em: 27 jun. 2013.

HUGES, A. Testing for Language Teachers. Cambride: Cambridge University Press: 2003.

LIMA, F.; LUNA, R.P. Pensando o vlog como gênero textual aplicado ao ensino. In: III Simpósio Nacional de Linguagens e Gêneros Textuais - III SINALGE, 2012, Campina Grande. Linguagens, gêneros e discursos. João Pessoa: Ideia, 2012. v. 1. p. 638-649.

LIMA, F.; PINHEIRO-MARIZ, J. A personagem Formiga em fábulas de La Fontaine: uma abordagem em aulas de francês como língua estrangeira. Revista Letras Raras, Campina Grande, v. 1, n. 1, p. 79-94, 2012.

Lizzie Bennet: a modern adaptation of Pride and Prejudice. Disponível em: <http://www.lizziebennet.com/> Acesso em: 27 de jun. de 2013.

LUCKESI, C. C. Avaliação da aprendizagem escolar: estudos e proposições. São Paulo: Cortez: 2011.

PERNIGOTTI, J. M. et. al. O portfólio pode muito mais que uma prova. Revista Pátio, Osasco, n. 12, p.54-56, abr. 2000. 